https://helda.helsinki.fi

\title{
Facial expression and interactional regulation of emotion
}

\section{Peräkylä, Anssi}

Oxford University Press

2012

Peräkylä , A \& Ruusuvuori , J E 2012 , Facial expression and interactional regulation of emotion . in A Peräkylä \& M-L Sorjonen (eds), Emotion in Interaction . Oxford University Press , Oxford, pp. 64-91.

http://hdl.handle.net/10138/157554

Downloaded from Helda, University of Helsinki institutional repository.

This is an electronic reprint of the original article.

This reprint may differ from the original in pagination and typographic detail.

Please cite the original version. 
CHAPTER 4

\title{
abs \\ Facial Expression and Interactional Regulation of Emotion
}

\author{
ANSSI PERÄKYLÄ AND JOHANNA RUUSUVUORI
}

\begin{abstract}
mong the channels of expression in multimodal interaction, the face is special because it is, arguably more than the other channels, specialized in one task. This task is to convey emotion (see Ekman, 2009, p. xxii). Other channels of expressionbe they lexical choices, syntactic structures, prosody, gestures, spatial movements, or the like-can be used in this task (see e.g., Besnier, 1990, and this volume, introduction), but they also perform a multitude of other tasks. Facial expression predominantly conveys what we feel about something. In this chapter, we will explore ways in which facial expression of emotion is organized in relation to another modality, spoken utterances, at a particular juncture of social interaction: at a closure of a story, anecdote, or other kind of telling. In our examination of facial expression, a key issue for us is regulation of emotion - one of the hot topics of current psychological emotion research (see e.g., Gross, 2007; Vandekerckhove, von Scheve, Ismer, Jung, \& Kronast, 2008).
\end{abstract}

\section{REGULATION OF EMOTION IN INTERACTION}

Usually, the regulation of emotions is conceived as an individual competence, involving "the process by which individuals influence which emotions they have, when they have them, and how they experience and express these emotions" (Gross, 1998, p. 275). According to Gross and Thompson (2007, pp. 10-16) this process has five facets. Situation selection involves seeking or avoiding occasions that might arouse emotions, situation modification involves efforts to change such situations, attentional deployment involves directing one's attention in ways that influence emotions, cognitive change has to do with the ways in which individuals 
appraise the emotional meaning of the situation at hand, and response modulation involves efforts to change the physiological, experiential or behavioral responses to the situation.

The view of Gross and Thompson (2007), as well as most other research on emotion regulation, is individual-centered, focusing mostly on the ways in which individuals influence their own emotions. But emotion regulation can also be seen from a more sociological perspective. Without using the emotion regulation vocabulary, Hochschild (1979) had already in the 1970s elucidated the social dimension of regulatory phenomena, by suggesting that in social situations, individuals apply culturally derived feeling rules to adjust their emotions to what is understood as appropriate in a given situation or setting. Likewise, in their theory of facial expression of emotion, Ekman and Friesen (1969) suggested that culture-specific display rules influence the way in which individuals, in presence of others, modify the biologically given facial expressions of different emotional states. Hochschild, and Ekman and Friesen (whose theories otherwise are far apart) thus agree on the view that sociocultural factors influence the way in which individuals regulate their emotional experience and/or its expression. (See also Bloch, 2008; Mesquita \& Albert, 2007; Poder, 2008; Trommsdorff \& Rothbaum, 2008.)

Our conversation analytical conceptualization of the role of facial expression in the regulation of emotion differs from both the psychological and the sociocultural views. Rather than tracking the ways in which individuals influence their own emotions, or the cultural and social motivators of regulation, we examine interactional regulation (cf. Beebe \& Lachmann, 2002). This involves the ways in which participants in interaction influence each others' emotions in situ. We focus on the ways in which the expressions of emotion are on the one hand regulated by the contingencies of the social situation, and how they on the other hand influence the unfolding of that situation.

Although our basic understanding of emotion regulation is different from the psychological, individual-centered view and the cultural view, we believe that our findings complement rather than contradict these other approaches. In terms of the emotion-regulation process model of Gross and Thompson, our primary focus is in response modulation. By examining the interactional dynamics of the facial expression, we will show some ramifications of the modulation of what Gross and Thompson would call behavioral emotional response. However, as we will show in the concluding discussion of the paper, our findings also contribute to the understanding of other facets of emotion regulation process: situation modification, attentional deployment and cognitive change.

\section{PURSUING A RESPONSE TO TELLING}

Stories, anecdotes, and other kinds of telling usually involve a display of stance by the teller to what is being told, and make relevant the recipient's affiliation or 
disaffiliation with that stance (Jefferson, 1988; Maynard, 2003; Maynard \& Freese, this volume, chapter 5; Couper-Kuhlen, this volume, chapter 6). A stance qualifies the telling with a positive or negative valence, depicting what is being told, for example, as funny or sad. In this chapter we explore the ways in which facial expressions convey stance: how they show the storyteller's own stance toward her telling and give hints to the recipient about an appropriate way to receive the story through an assessment or other stance display.

Our interest lies in a specific type of moment of the telling sequence: occasions where a story or a telling is coming to its closure and a response is due, but it is delayed. This is an environment that potentially threatens the maintenance of alignment and shared understanding as well as the existing level of intimacy between the participants (cf. Jefferson, Sacks, \& Schegloff, 1987). Consequently, the interactional regulation of emotion is dense in these occasions. As we will show, facial expression is a key means for emotion regulation here.

Anita Pomerantz (1984a) has examined a conversational sequence similar to ours in telephone calls. She examined the lack of recipient uptake to what she, in quite broad terms, called "assertions," and showed how the speakers may deal with the lack of response. Typically, the speakers clarify or revise the telling, whereby they, in Pomerantz's terms, "pursue response." This offers a point of comparison with the phenomenon that we examine in face-to-face conversations. By examining the facial expressions of the participants at the closure of tellings, such as complaints, anecdotes, and self-blaming remarks, we show what sort of particular relevancies facial expression can create for the upcoming response. In this way, we hope to bring to view an instance of what we call the "interactional regulation of emotions."

\section{DATA AND METHOD}

Our data consist of five video recordings of conversations over lunch in dyads of female friends. Out of these recordings, we found forty instances of the phenomenon under scrutiny: an interlocutor has made an assertion (a story, an anecdote, a remark) that makes relevant the recipient's response, the response has been delayed, and the interlocutor observably changes her facial expression, slightly turning her head toward the recipient. We call this combination of movements within the above-mentioned sequential location facial pursuits.

The recordings were made in a cabinet of a student refectory, where we invited the participants to have their ordinary daily lunch. They were seated half-toward each other, one at the end of the table, the other at the side of it (see Figure 1). This way they were able to notice if the other participant made a gesture, such as a head-turn to seek engagement, even when gazing away from the coparticipant (Goodwin, 1986). 


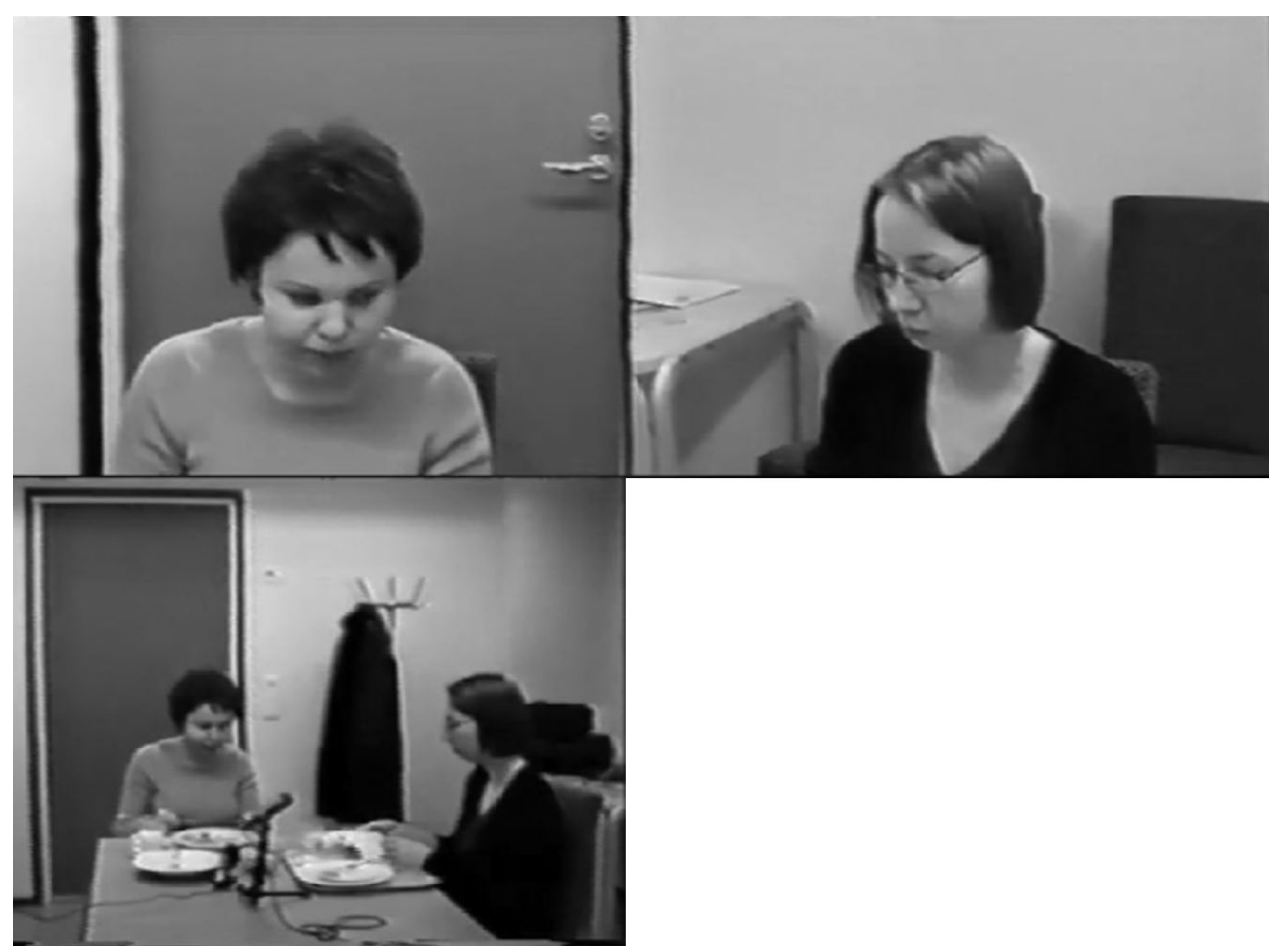

Figure 1

The setting

In what follows, we will explicate the interactional work that facial expressions do when response to a telling with a stance is delayed. By specifying some ways in which facial pursuits of response differ from verbal pursuits, we seek to show the specific affordances of face as means of pursuit of response.

We will start by showing an example of verbal pursuit of response to a story.

\section{PURSUING RESPONSE VERBALLY}

Consider the following example.

Extract 1

01 B: EHẹmmetti mää oon jo ihan sillai .hh nyrkki [ojossa

$£$ Bloody hell I'm already like kind of.hh shaking my [fist

02 A:

[ehhe

03

B: siellä£ mutta tota, there£ but like, 
05 B: Se vilahti just jonneki lattian rakoon nyt täytyy [alottaa

It just rushed somewhere to a slit in the floor now I must [start

06 A:

$[\mathrm{Mmm}$,

07 B: uus sota ilmeisesti.

a new war I suppose.

08 A: $\quad \mathrm{Mm} / \mathbf{F i g} \mathbf{2} / \mathrm{m}$.

$09 \quad \rightarrow \quad(1.5)$

10 B: Hịt [to vie semmonen joku uus yhdyskunta./Fig 3/

$\rightarrow$ Da $[\mathrm{mn}$ it some sort of like a new colony./Fig3/

11 A: $\quad[M m m$,

$12 \quad(2.2)$

13 A: $\quad{ }^{\circ} N_{i i h}{ }^{\circ}$ no > ku niil on< (0.4) päämajana se mun viemäristö

${ }^{\circ}$ Right ${ }^{\circ}$ well >as they have< (0.4) their headquarters in that sewer of mine

14

$n$ [i ne on varmaan sieltä Eputkia myöten tullu£..hhhmth

$\mathrm{s}$ [o they must have crawled from there £along the pipes£..hhhmth

15 B: $\quad[\underline{h h m h}$

Prior to the extract, B has been telling a story about how she has tried to get rid of bugs in her sewer-with no real success. The story seems to have entailed two different stances toward the events described: on the one hand the teller has been laughing at her "warfare" against the bugs, while on the other, she has been telling about a real problem (see Ruusuvuori \& Peräkylä, 2009). During the production of the story, A has appreciated its humor by laughing and smiling (Ruusuvuori \& Peräkylä, 2009; see line 2). At the completion of the story, however, she remains rather silent, producing only two acknowledgement tokens (lines 6 and 8). At most, this constitutes a very minimal reciprocation of emotional stance at the completion of the telling.

There then follows a gap (line 9), after which B adds an exclamation-like closing element to her story (line 10). With this element, emphasizing perhaps more the troublesome than the humorous nature of her experience, she verbally pursues a further uptake of her story. Following a gap of 2.2 seconds, A continues the topic by offering a humorous explanation to B's continuing problem, thereby more fully reciprocating the stance of the telling.

The two frames, Figures 2 and 3, show the participants' facial expression before and during the verbal pursuit (lines 8 and 10). In all frames, participant $A$ is on the 
left, and participant B on the right. At the end of the story in Extract 1, the recipient withdraws her gaze from the teller (see Figure 2).

A

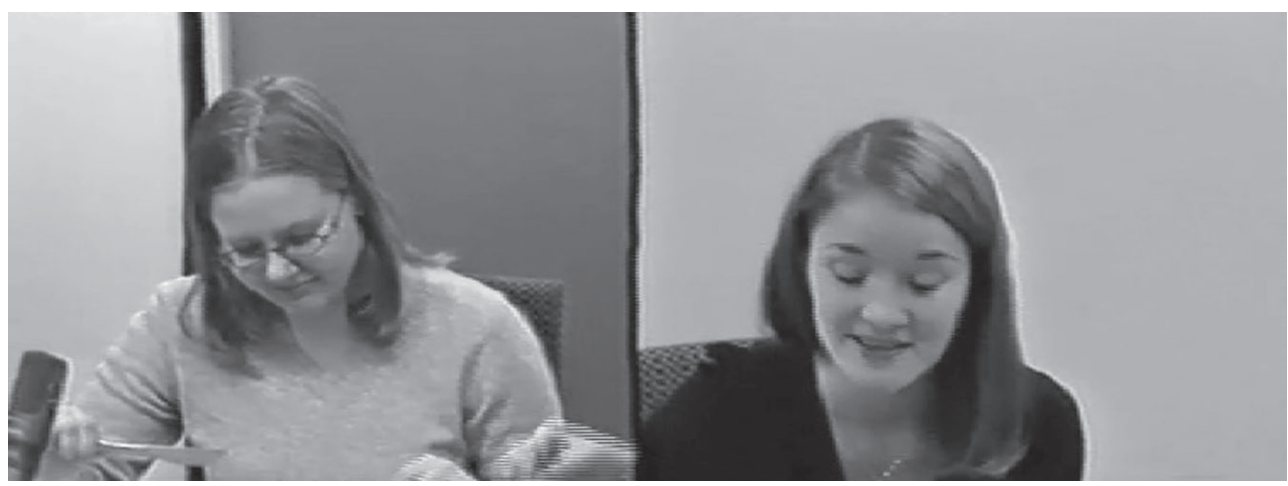

Figure 2

08 A: Mm/Fig2/m.

During the verbal pursuit and the subsequent silence, the participants are disengaged from one another, gazing at their food. Their faces are straight, without observable emotional expression (see Figure 3).

\section{A}

\section{B}

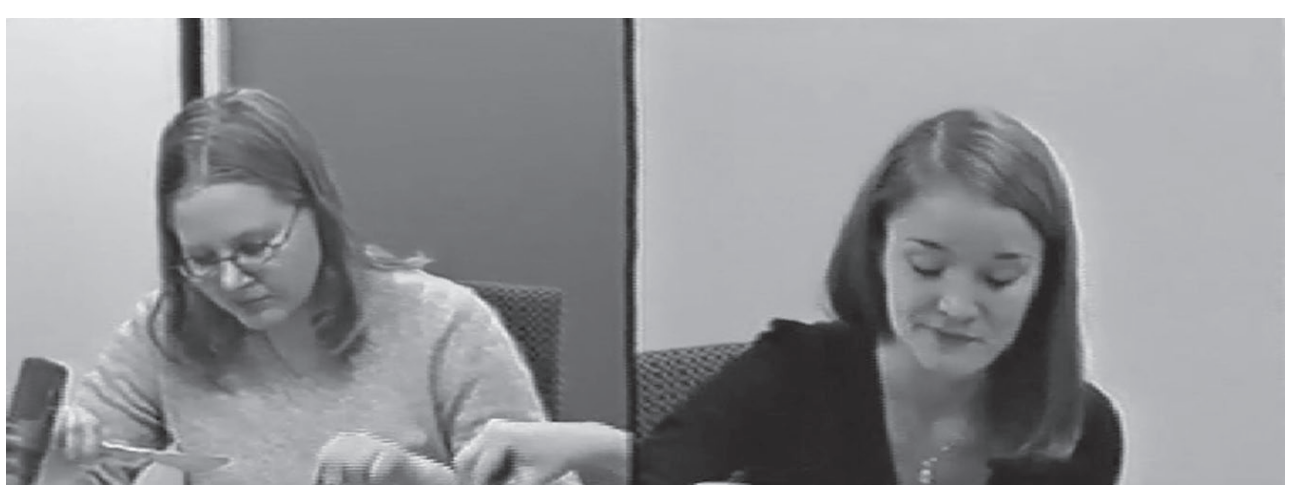

Figure 3

10 B: $\mathrm{Da}[\mathrm{mn}$ it some sort of like a new colony. /Fig3/

Thus, in this case, the pursuit of response to a story occurs predominantly, if not only, through verbal means.

In the following we will present variations of facial pursuits in a location comparable to the one where the facial pursuit occurred in Extract 1. First, we will examine segments of interaction where the facial expression reinforces the stance displayed in 
the telling, then a case where the facial expression explicates emotional stance that in the telling is left implicit, and finally, we will examine a case where the facial expression modifies the emotional stance displayed in the telling.

\section{REINFORCING STANCE THROUGH FACIAL EXPRESSION}

Consider Extract 2, in which facial pursuit reinforces the emotional stance of a troubles telling. At the beginning of the extract, B is coming toward the end of a story in which she tells about her failure to get an appointment at the student health center. The complaining stance of the story (see Drew, 1998) unfolds as the telling proceeds. The temporal references in the story (lines 6-9) implicate the time of the telling, which is at the end of November.

B's story is hearably at its completion in line 9, through an utterance in which B reports, using a mocking voice (Günthner, 1997a; Holt, 1996; Haakana, 2007), the answer she got from the representative of the organization. The recipient, however, does not produce an immediate response (lines 10-12). But after the gap, she gives an affective evaluation of the story (line 13).

\section{Extract 2}

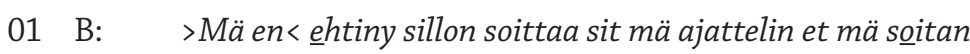

$>$ I didn't have< time to call then so I thought I'll call

02

maanantaina,

on Monday,

$03 \mathrm{~A}: \mathrm{Mmm}$,

$04 \quad(0.7)$

05 B: Soitin maanantaina varmaan joskus yheksäl/Fig4/tä

I called on Monday about like ni/Fig4/ne o'clock

06

$\begin{array}{llllll}\text { aamul? .mthhhh } & @ J o o & k \underline{a} i k k i & \text { tota joulukuun } & \text { ajat } \\ \text { morning+in } & \text { yes all } & \text { PRT } & \text { December's times }\end{array}$

in the morning?.mthhhh @yes all like appointments for December

07

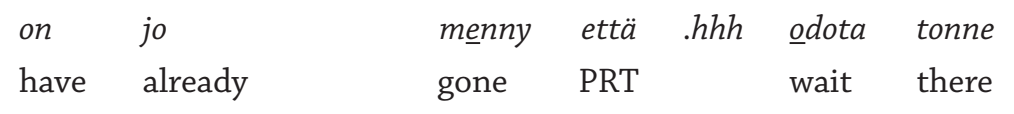

are tạken already so that.hhh waiit until around

$08 \rightarrow$ joulukuun [püoleen väliin ja soita sịtte ja/Fig5/ koita varata

December's [half+to distance+to and call then and try to+book

mid-December and call then and /Fig5/try to make

[((A withdraws her gaze)) 


$$
\begin{aligned}
\rightarrow \text { tammikuulle } & \text { se }\left[a i^{\circ} \mathrm{ka} . @ / F i g 6 /\right. \\
\text { January+to } & \text { the [appointment }
\end{aligned}
$$

the appointment for January.@/Fig6/

$[(($ A returns her gaze $))$

11 B: .mthhh

13 A: Siis /Fig9/voi plïis oikees/Fig10/ti, Like /Fig9/c'mon really no/Fig10/w,

15 B: $\quad$ Mmmm. hhe

We shall now examine the intensive facial work that the participants are engaged in. The storyteller has maintained her gaze toward the recipient through the final part of the narrative, without any lapse from the end of line 5 (see Figure 4).

A

B

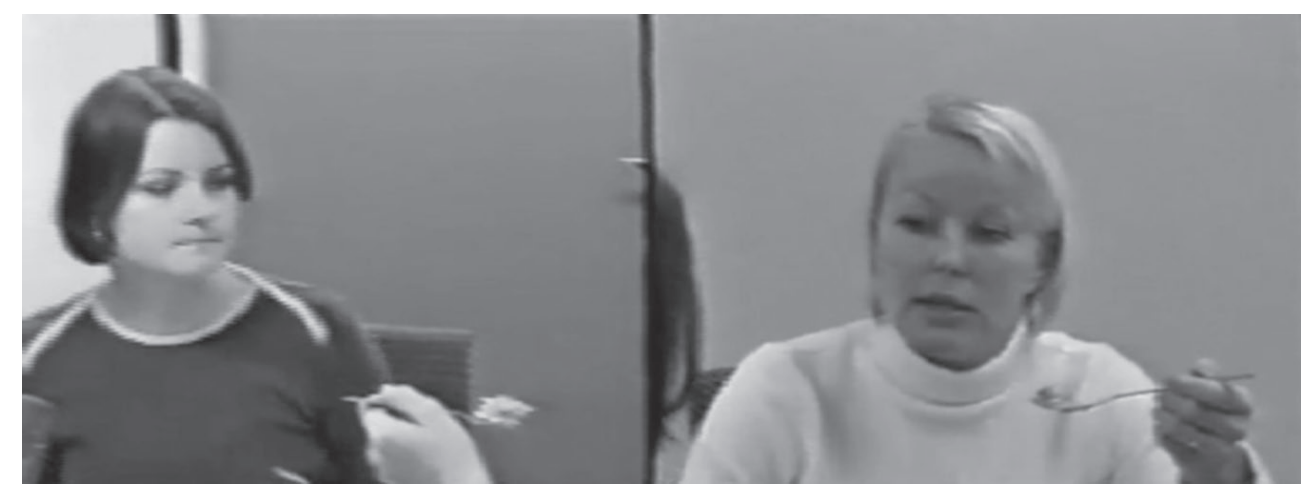

Figure 4

05 B: I called on Monday about like ni/Fig6/ne o'clock

A, the recipient, however withdraws her gaze (after the word "December") for a moment during the citation which serves as a story climax (see lines 8 and 9). During her disengagement, she gestures in an ambiguous way, bringing her right hand, fingers bent, in front of her mouth, and moves them as if she were scratching her upper lip (see Figure 5). While the postural disengagement incorporates lack of engagement in the story (during its climax), the gesture on the other hand can be received as conveying emotional stance, treating what is being told as ridiculous. 
A B

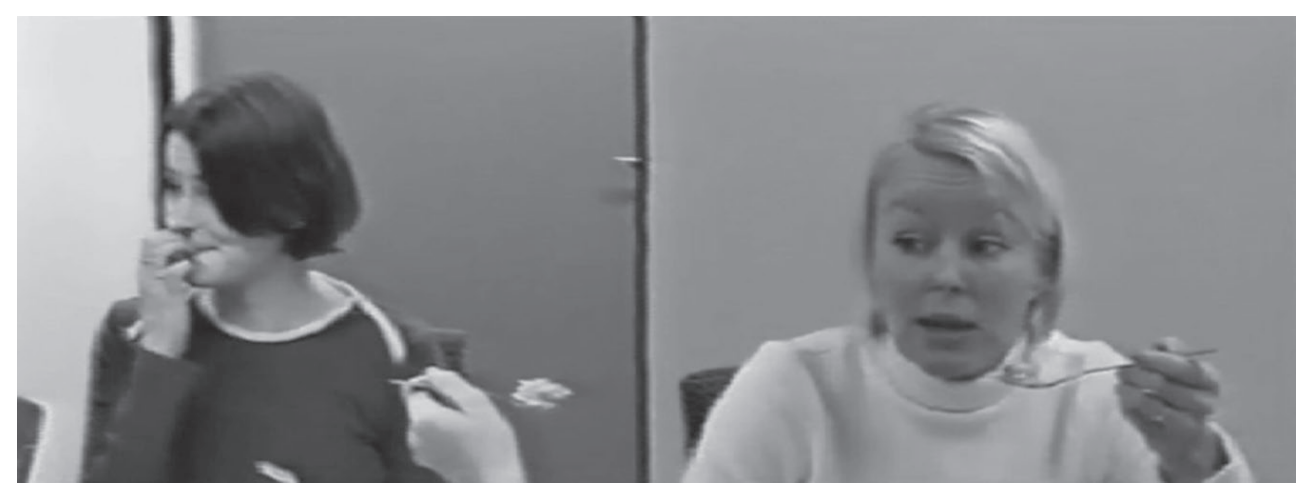

Figure 5

08 B: call then and /Fig5/ try to make the appointment

By the final word of the reported answer (line 9), A has returned her gaze to the story teller. She does not, however, initiate any talk, and her face is non-affective (see Figure 6).

A B

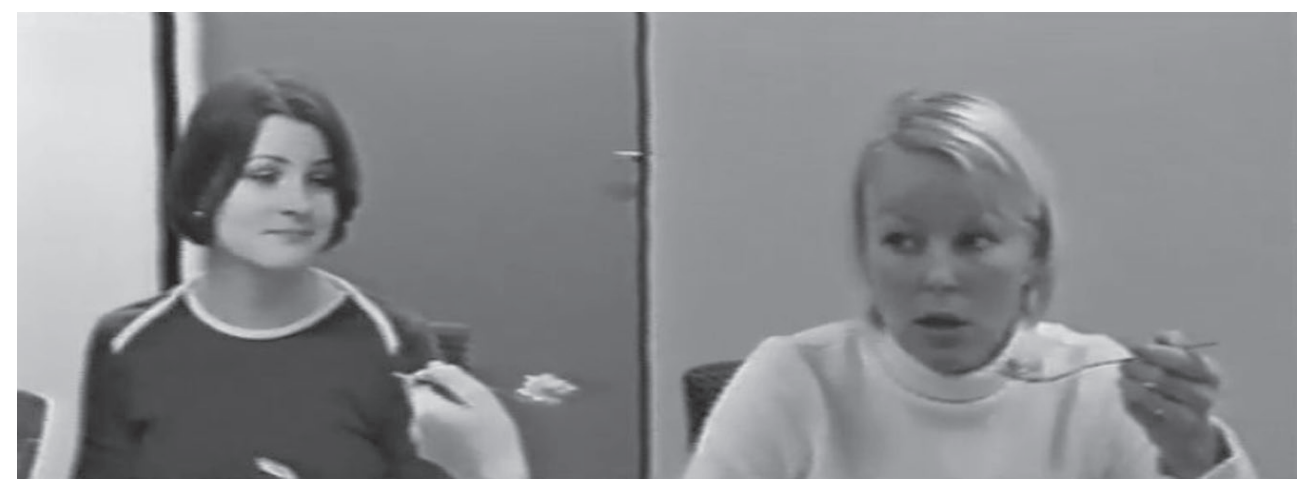

Figure 6

09 B: the appointment for January.@ /Fig6/

At the completion of her utterance (line 9), and during the silence that ensues (line 10) B produces an animated facial expression (observe the change from Figure 5 to Figure 6), conveying an affect which might be formulated like "this is appalling and unbelievable" (see Figures 6 to 8).

This expression serves as a pursuit of response. B leaves her mouth open, as it was at the end of her last word aika ("appointment"). Then, while continously gazing at A, she turns her head in two phases more directly toward A. B's mouth remains open and a bit round, her eyebrows are up and eyes become bigger and "round" (Figure 7). In response, $A$ (who maintains her gaze at $B$ ) raises her eyebrows (Figure 8). During the change in A's expression, the affect display on B's face seems to get more intensive; the impression is probably due to her second head movement toward A, and the way in which she maintains the same expressive features over a period of time (Figures 7-8). Toward the end of the silence in line 10, B withdraws her gaze from $A$ and breaths in (line 11). After a gap, A, who maintains her gaze at B, then starts a verbal, 
affective evaluation of the story (line 13; Figure 9). During the last word of her evaluation (oikeesti, "really"), A also withdraws from visual orientation toward the coparticipant (see Figure 10).

A B

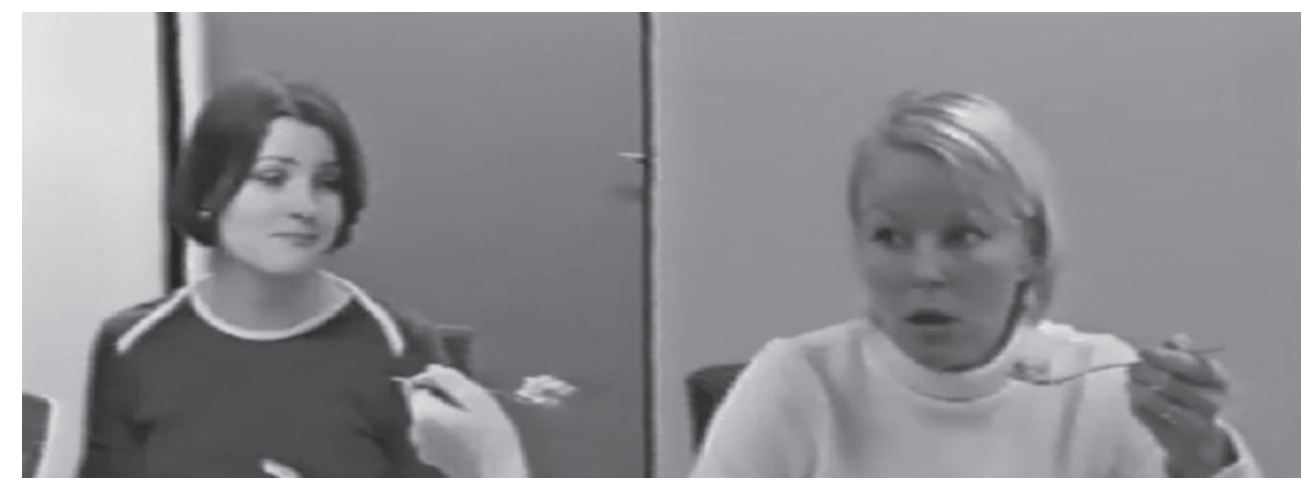

Figure 7

Silence in line 10

\section{A}

B

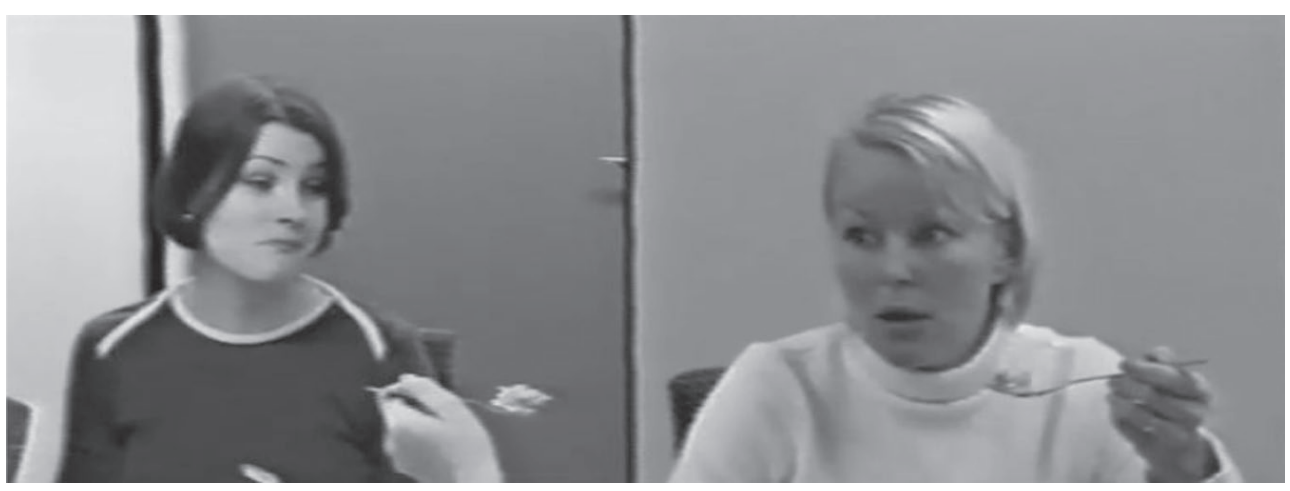

Figure 8

Silence in line 10

\section{A}

B

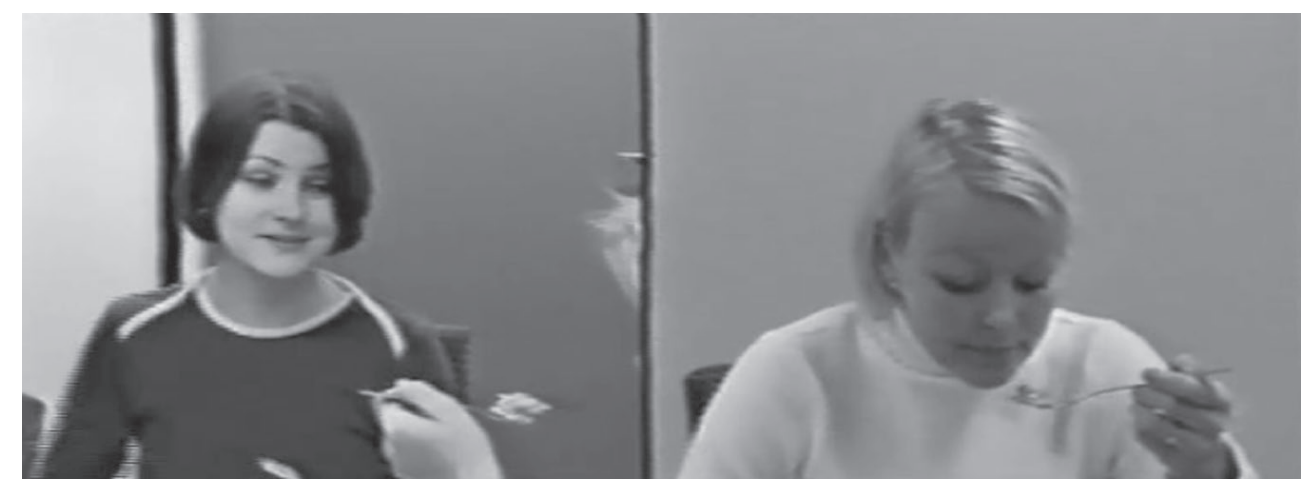

Figure 9

13 A: Like /Fig9/ c'mon really now, 
A B

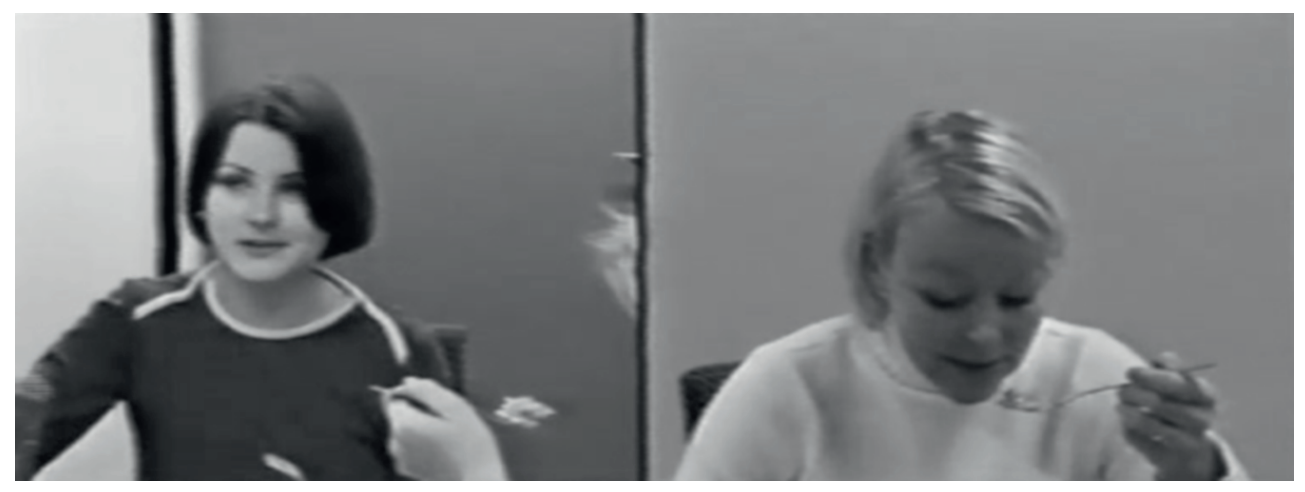

Figure 10

13 A: Like c'mon really no/Fig10/w,

The two cases we have now seen are similar in many respects, but yet contrastive. In Extract 1, at the hearable completion of the story, the teller and the recipient are disengaged in terms of gaze. In absence of adequate response from the recipient, the teller pursues response through adding a new verbal element-which preserves the emotional stance of the telling - to the narrative. In Extract 2, the participants are in mutual orientation at the completion of the story. In absence of adequate response, the teller pursues response through maintaining and intensifying the facial expression that was on her face at the completion of the telling and by making her facial expression more available to the coparticipant by turning her head further toward her. The facial expression preserves the emotional stance that was embodied in the telling. So, we see two ways of pursuing an emotional response to a telling.

In a verbal pursuit, the teller produces a new unit of talk-a new turn constructional unit (Sacks, Shegloff, \& Jefferson, 1974) — thereby also creating a new transition relevance place (Sacks et al., 1974) after the pursuit, where the recipient's response is relevant. Place for response is thus, as it were, postponed, and created anew. The response to be produced in the new transition relevance place is a response not only to the telling as it initially was (i.e., the telling as it was before the first transition relevance place) but it is a response to the talk that has been revised through the new element. We can see this in Extract 1: B's response, as it eventually comes forth in lines 13-14, does not focus on the activities of A, which were the focus at the first possible completion of the story in lines 5 and 7 ("now I must start a new war I suppose"), but rather, on the properties and whereabouts of the bugs, which was the focus of the verbal pursuit in line 10: "Damn it some sort of like a new colony". Thus, in pursuing the response through verbal means, the speaker inevitably invites response to a transformed telling.

The place and relevancies for response in facial pursuits are different. As the teller does not add anything to her talk, she also maintains, more than in verbal pursuits, the initial relevancies regarding the response. As we have argued elsewhere (Peräkylä \& Ruusuvuori, 2006; Ruusuvuori \& Peräkylä, 2009), the facial pursuit of response stretches the boundaries of action. This means that in a facial pursuit, the initial 
sequential place for launching the next action is maintained. The facial pursuit reinforces, explicates, or modifies the stance of the initial telling, but it does not change the verbal telling per se. In consequence, the response, when it eventually occurs, is a response to the telling as it was initially delivered. Thus, in Extract 2, when A eventually responds in line 13 by saying "Like c'mon really now", she is hearably commenting upon what the student health center receptionist said, as mockingly cited by B in lines 6-9.

So, the choice between verbal pursuit and facial pursuit might also entail a choice between inviting a response to talk that the verbal pursue has somehow renewed, and a response to the talk as it initially was. The latter choice may sometimes have interactional benefits: it gives the recipient an opportunity to show affiliation with and understanding of the stance of the telling earlier in the sequential time, at the very transition relevance place where it initially is made relevant. If the participants take up this trajectory, they may preserve their joint action and the shared stance toward the object of evaluation with minimal rupture to the progressivity of the interaction.

In Extract 2, the facial pursuit maintained and intensified the affective stance that the speaker had displayed in her preceding utterance, response to which was pursued. In Extract 3 below we see a parallel case. As Extract 2, it also involves troubles telling. In Extract 3, however, the facial pursuit does not alone manage to elicit an affective response.

A is talking about a commitment she gave to an organization to produce a piece of research in a given time, pointing out how the commitment made her feel tied. The telling is part of a larger set of A's narratives all describing her difficulties in coping with her writing tasks. In response to B's affectively dense description (see the word choices "horrified," "help," and "completely tied") of her helplessness in lines 1-2, the recipient produces two somewhat delayed $m m$-tokens (line 4 ). The response is less than fully engaged, albeit the soft voice quality and even intonation in especially the latter token make it hearable as minimally empathizing. A's narrative about this particular piece of research reaches a point of completion in line 3 : she discontinues her sentence "now I'm like", and after a 0.3 second pause, produces an idiomatic expression describing an untoward situation, tässä sitä ny ollaan (literal translation, "here we are now"). The idiom brings the telling hearably to completion (see Drew \& Holt, 1988) and makes display of affiliation by the recipient relevant (see also Jefferson, 1988). After the closure of the telling, a gap ensues, whereafter B offers in line 5 a response token nii (line 6). The voice quality and the intonation contour of the nii are close to those in the latter $m m$-token in line 4 , but as lexical choice, nii is arguably more affiliative than $\mathrm{mm}$ (Sorjonen, 2001, chapter 6). B does not, however, offer any more elaborate verbal display of understanding the trouble (cf. Ruusuvuori, 2005; Voutilainen, Peräkylä, \& Ruusuvuori, 2010a; Heritage, 2011). A does not treat the minimal display of affiliation as sufficient, as she enters into verbal pursuit (line 7) through an incremental element that clarifies when her anxiety started, thereby treating the lack of response as a problem of unclear reference (cf. Pomerantz, 1984a). The recipient remains rather passive (line 8) and only after the narrator has made further verbal pursuits in which she shifts her position (cf. Pomerantz, 1984a) to a more normalizing one (lines 9, 11, and 13) does the recipient 
launch a more elaborate response (lines 14-15) in which she seems to reciprocate primarily the normalizing stance.

Extract 3

01 A: No sịtte mulle tuli siitä semmone jotenki /Fig11/ hirvitys PRT then me+to came it+from such somehow horror Well then it made me sort of /Fig11/horrified

02 että apua että ny[t mä oon ihan sidottu sii[hen että /Fig12/ PRT help PRT no[w I am completely tied th[at+to PRT that help that no[w I am completely tied to th[at so /Fig12/

\section{$[(($ A gazes at $B))$}

[((mutual gaze))

03 nyt [mä oon niinku (0.3) e[ttä tässä sitä ny ollaan./Fig13/ now $[\mathrm{I}$ am PRT [PRT here PRT now are+we now[I am like (0.3) [so that here we are now./Fig13/

04 B: $[\mathrm{Mmm} . \quad[\mathrm{Mmmm}$,

$05 \quad(1.2) /$ Fig14//Fig15/

06 B: Nii, /Fig16/

Yeah, /Fig16/

07 A: Ku mä niinku lähetin ne /Fig17/ pape ${ }^{\circ}$ rit $^{\circ}$.

As I sent the $/ \mathbf{F i g 1 7} / \mathrm{pa}^{\circ}$ pers ${ }^{\circ}$.

08 B: $\quad M m m[m m m m$.

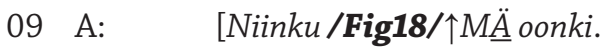

[So /Fig18/ $\uparrow \underline{I}$ am indeed.

10 B: $M m \underline{m m m}[\mathrm{mmmm}$.

11 A: [Mikä ei sinnänsä se[n pitäs olla niinku

[Which isn't in itself $\mathrm{i}[\mathrm{t}$ should be like

12 B: $\quad$ [.hhhh

13 A: positiivin [en juttu. .mt Mutta.]

A positi [ve thing. .tch But.]

14 B: [.mt Nii nii et se sitoo sua $]$

[tch Yea yea so it ties you]

15 tẹkemään $[k i$ mutta.

also to [do it but.

16 A: [Niii.

[Yeah. 
We'll focus our analysis of the facial expression right after the completion of the telling. At the beginning of the extract, the participants are posturally disengaged, both gazing down (Figure 11).

\section{A}

B

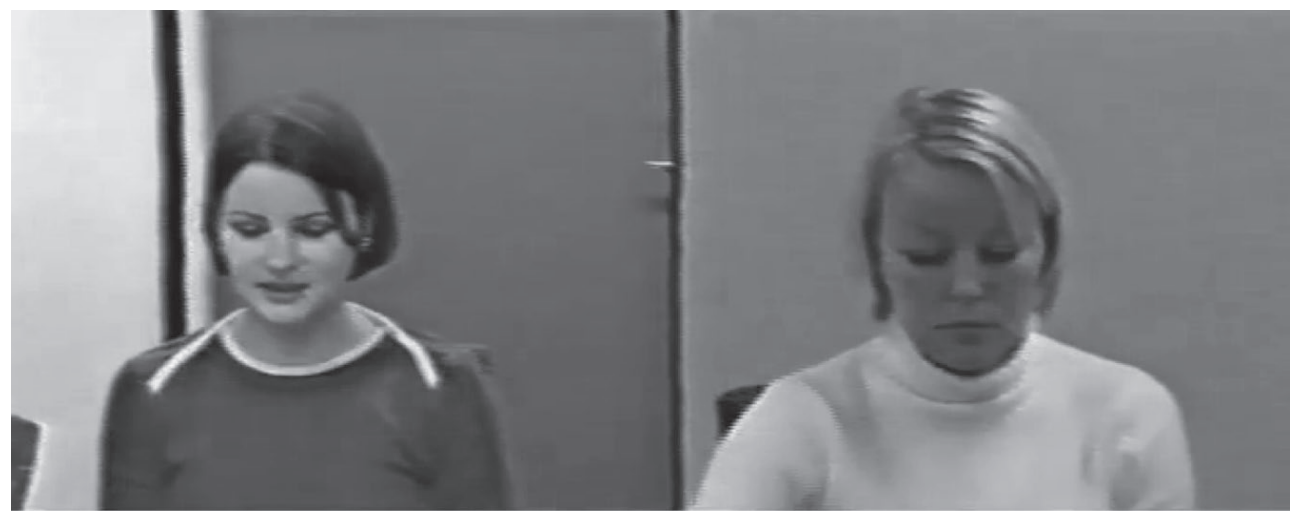

Figure 11

01 A: it made me sort of /Fig11/ horrified

When approaching the completion of the telling, in line 2, A shifts her gaze to B, who reciprocates the gaze at word siihen, "to that," and mutual engagement is thus established (Figure 12).

A

B

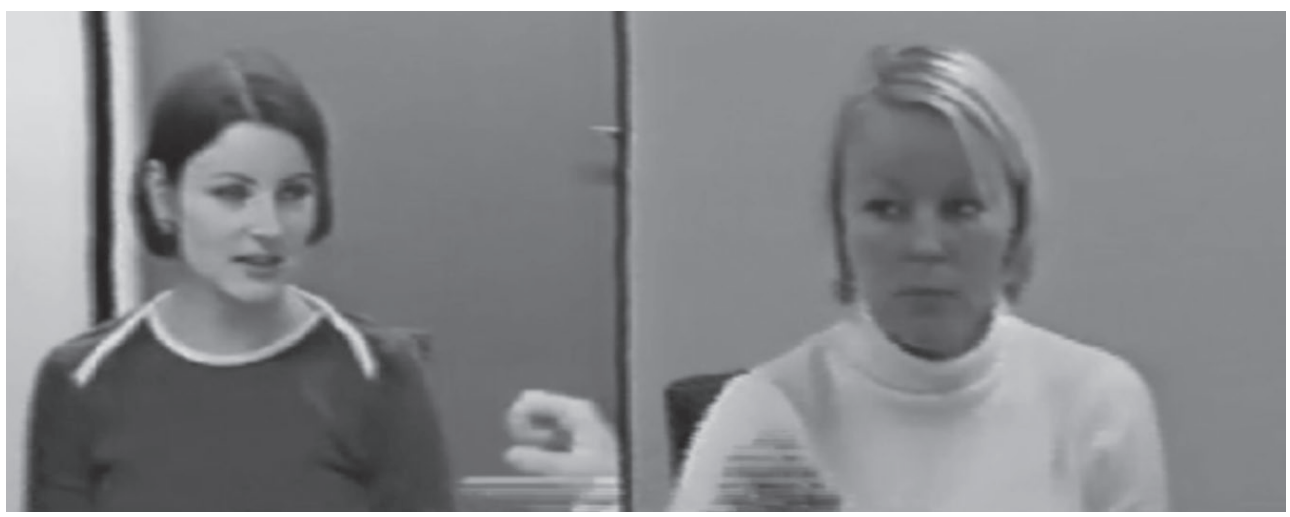

Figure 12

02 A: I am completely tied to that so /Fig12/

A produces the completion of the telling with a neutral face. Mutual orientation is maintained. At the closure of the telling (end of line 3), the participants are still gazing at one another. A's face remains affectively neutral while B is stroking her hair and purses her lips (appearing to be swallowing) (Figure 13). 
A

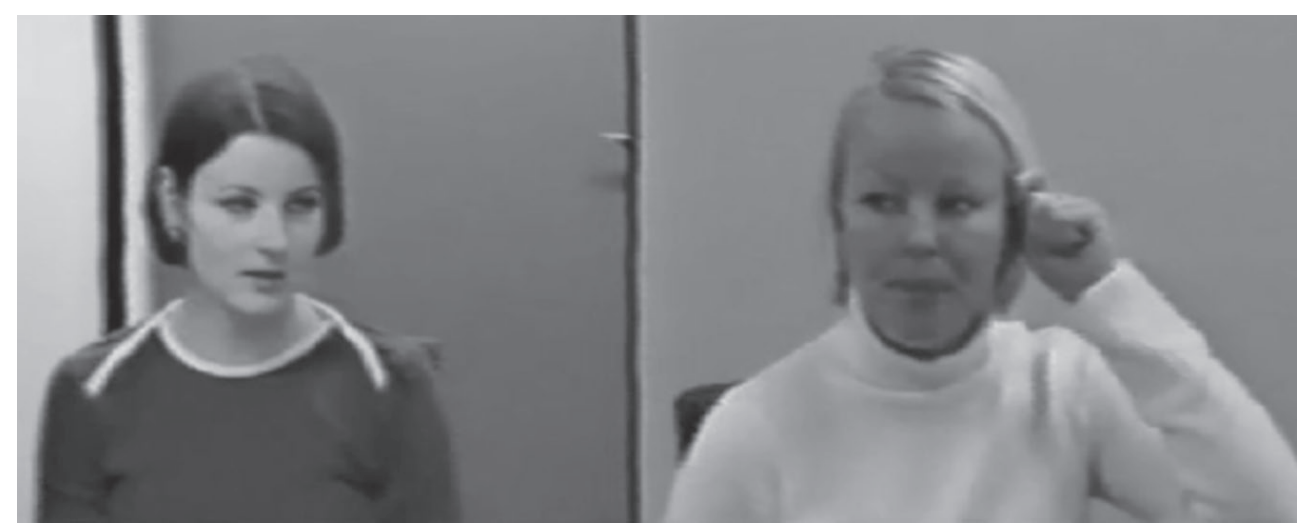

Figure 13

03 A: so that here we are now. /Fig11/

A silence (line 5) with intensive facial and gestural work ensues. After finishing her hair stroke, B tilts her head to right (Figure 14). Immediately thereafter, A raises her eyebrows, horizontal wrinkles appear to her forehead, she closes her mouth, bringing its corners slightly down, and tilts her head slightly forward toward the recipient (Figure 15).

A

B

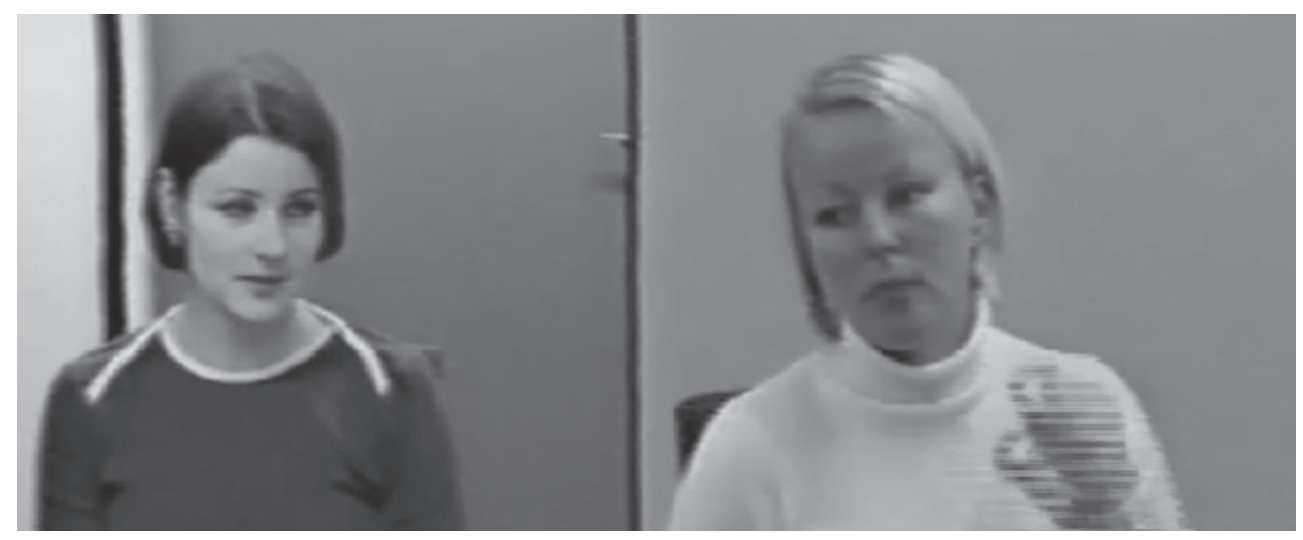

Figure 14

Silence in line 5

A

B

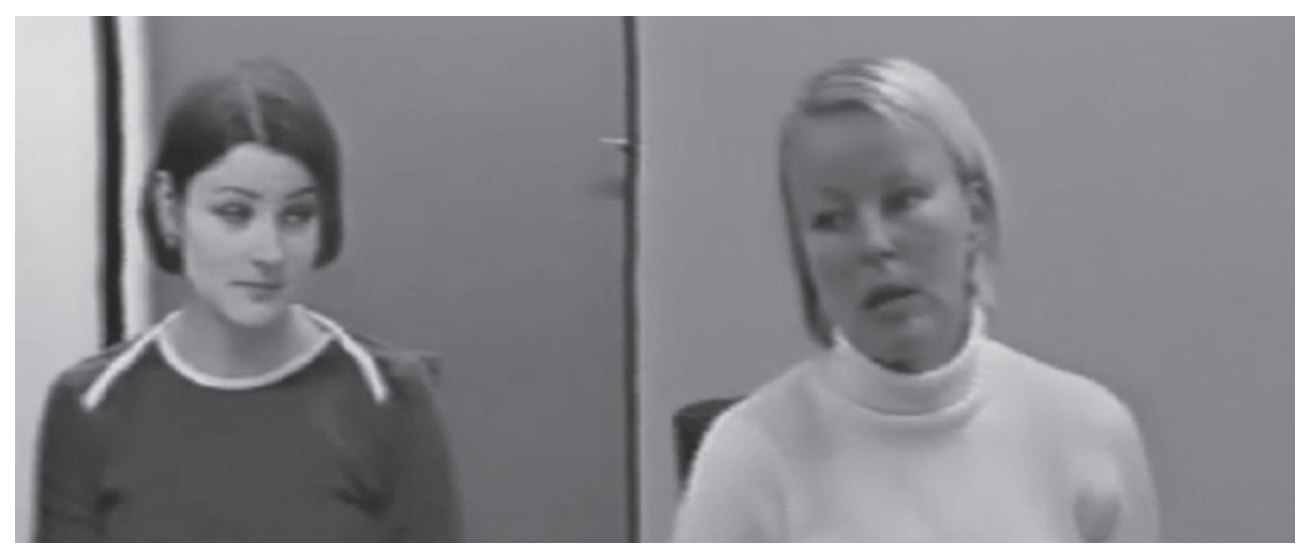

Figure 15

Silence in line 5 
A's facial expression serves as pursuit of response, and as in the previous example, the accompanying head move toward the recipient seems to make the face more available and prominent. Albeit clearly affective, A's expression appears not to convey a distinct, unambiguous emotion. In terms of Ekman and Friesen's (1975/2003) classificatory system, her expression has some affinity to sadness (Ekman \& Friesen, 1975/2003, pp. 119-121) and, on the other hand, to what they call questioning (Ekman \& Friesen, pp. 13, 39). The head tilt forward, and the consequent gazing of the coparticipant from a "lower" position, together with the raised brows, creates an impression of remorse or begging for understanding - something we might call appealing. As a whole, we might say, her expression creates a strong relevance for responsive action and the response that is elicited is marked as somehow affiliating with A's negative affect (conveyed by face in Figures 14 and 15, as well as the preceding utterance in lines 1-3).

In response to A's gesture, B produces her affiliating response token nii (line 6); A preserves her facial expression and posture while B produces the nii (Figure 16).

\section{A}

B

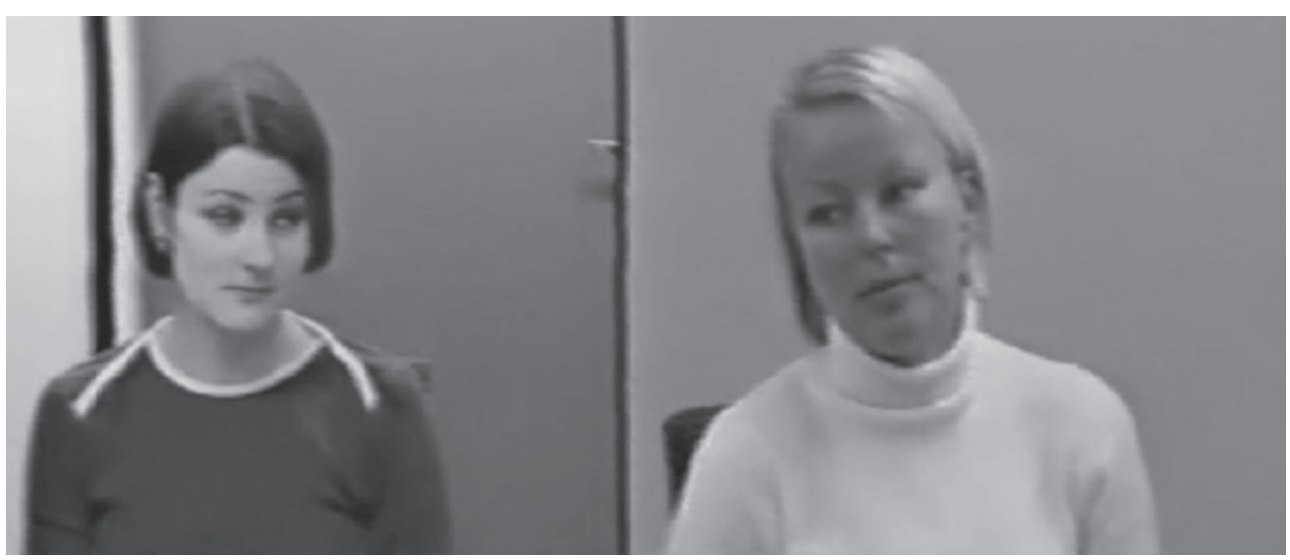

Figure 16

06 B: Yeah, /Fig16/

Her head position and brows remain in this position even when she produces the first verbal pursuit (line 7; Figure 17).

A

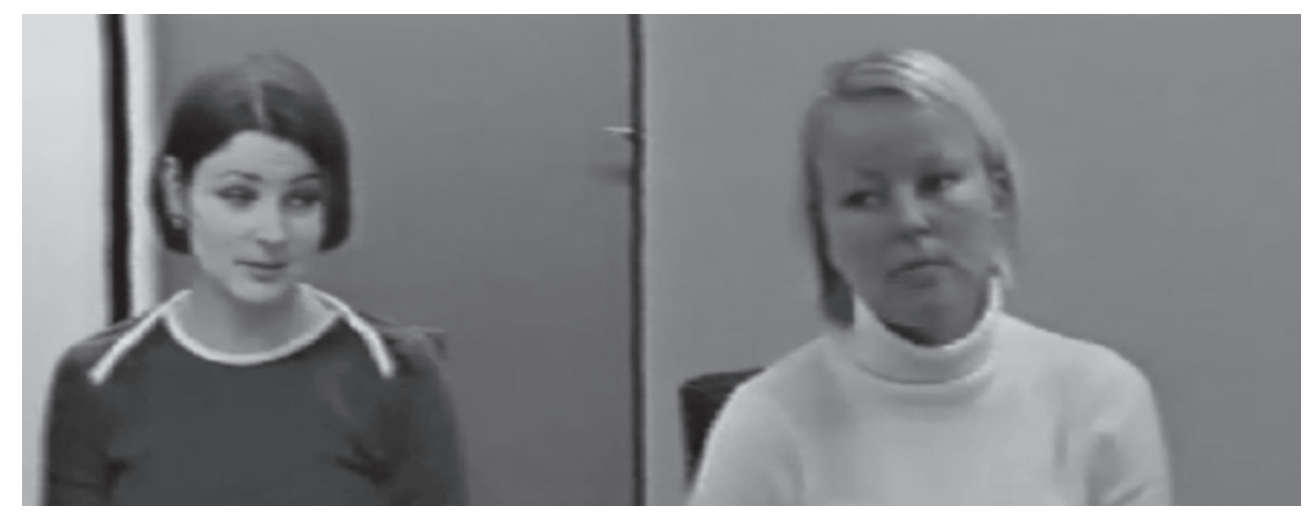

Figure 17

07 A: As I sent the /Fig17/ $\mathrm{pa}^{\circ}$ pers ${ }^{\circ}$. 
Only at the outset of her second verbal pursuit (line 9) her facial expression changes, as she tilts her head to left and starts to smile through her talk (Figure 18).

A

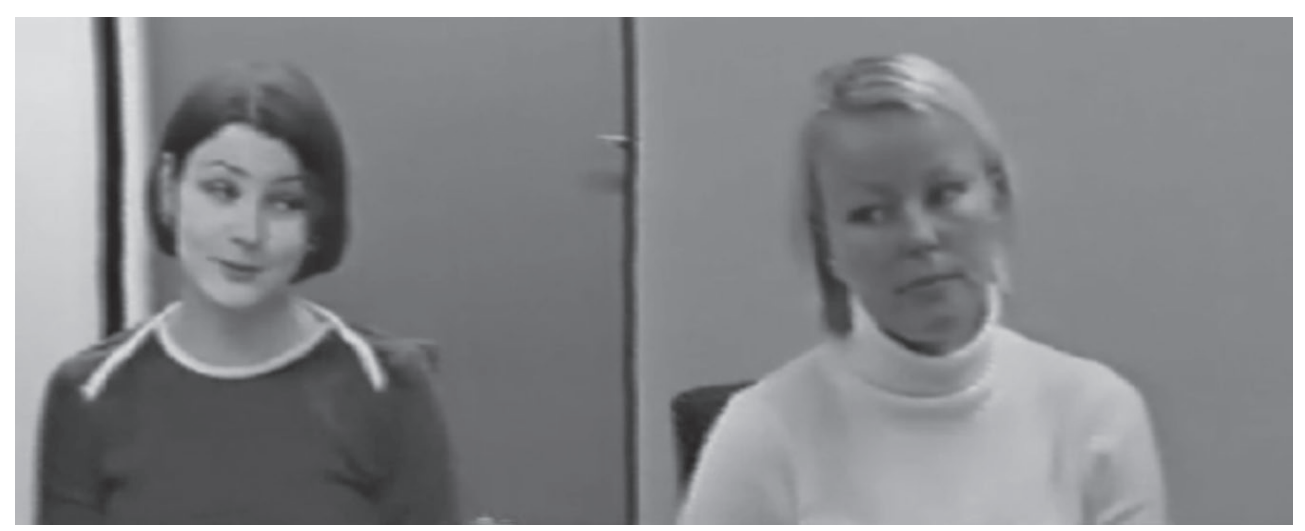

Figure 18

09 A: [So /Fig18/ $\uparrow \underline{I}$ am indeed.

In Extract 3, the verbal design of A's first utterance (word choices hirvitys, "horrified," apua, "help," and the use of the idiomatic exclamation tässä sitä ny ollaan, "here we are now"), as well as the position of the utterance as a completion of troubles telling, constitute the utterance as conveying negative emotion, characterizable as anxiety, helplessness, and self-blame. The postcompletion facial expression by A maintains this emotional stance and succeeds in eliciting a minimal, affiliating response to it. The response B gives after the facial pursuit is not, however, treated by A as sufficient, and she launches new verbal pursuits.

\section{EXPLICATING STANCE THROUGH FACIAL EXPRESSION}

In Extracts 2 and 3, the facial pursuits of response to tellings preserved an affective stance that was there already in the tellings. In a number of other cases, the relation between the facial stance display, and the telling, is somewhat more complex. In this section, we will examine an example of cases where the facial expression explicates a stance that was not quite manifestly put forward during the telling itself. The explication of stance through face seems to be a practice particularly apt to humorous tellings.

Consider Extract 4. A and B have just been talking about the recommendations that some employers have given to trainees for dress-code at work. They have laughed at a conservative employer who-according to a mutual acquaintanceprohibits male employees from wearing jeans (lines 1-2). After this, B in lines 4-6 shares something that she has heard about the dress code for women by this 
particular employer. After the informing there follows a delay of 1.2 seconds (line 7), after which A responds with a token of disbelief Eh: (line 8). An approximate English translation could be "No:". B starts a series of laugh tokens in overlap with A's response, and after B's laughter, A produces yet another vocalization $\underline{o h h h}$ (line 10) which resembles the first one but it uttered with more emphasis and perhaps through the change of vowel conveys stronger evaluative stance. A's response tokens (lines 8 and 10) convey that she considers what was told as foolish or unbelievable.

Extract 4

01 B: Sưorat housut vaaa.

Straight trousers only.

02 A: eh heh hehh he [he

03 B: $\quad$ [.hh Sit< tuon mie kuulin ihan Samilta intteltään

[.hh then< that I heard right from Sạmi himself

04 mutta (0.4) mie en muista se oli si-jokku múu joka oli sanonu but (0.4) I don't remember it was the- someone else who had said

05 et siel niinku süositellaan naisillekki

that there they also recommend to women

06 et ne [käyttäis/Fig19/ham ${ }^{\circ} e t t a^{\circ}$.

that they [should wear $/ \mathbf{F i g} \mathbf{1 9} / \mathrm{a}^{\circ}$ skirt $^{\circ}$.

[mutual gaze

$07 \quad$ (1.2)/Fig20/ / Fig21/ Fig22/

08 A: $\underline{\text { e }}[\mathrm{h} / \mathbf{F i g 2 3 / :}$

09 B: $[h m h h m h h m h h m h h m h h m h . h m h h h h$

10 A: .hhh öhhhh

11

12 B: Sellasta męnoa£.

That sort of buㅌsiness£

Toward the end of the informing (by the word käyttäis, "should wear"), the participants establish mutual gaze, B first turning to A, and A responding almost immediately by shifting her gaze to B. At this point, both participants have "straight faces", without observable emotional expression (see Figure 19). The facial neutrality persists to the end of the announcement. 
A

B

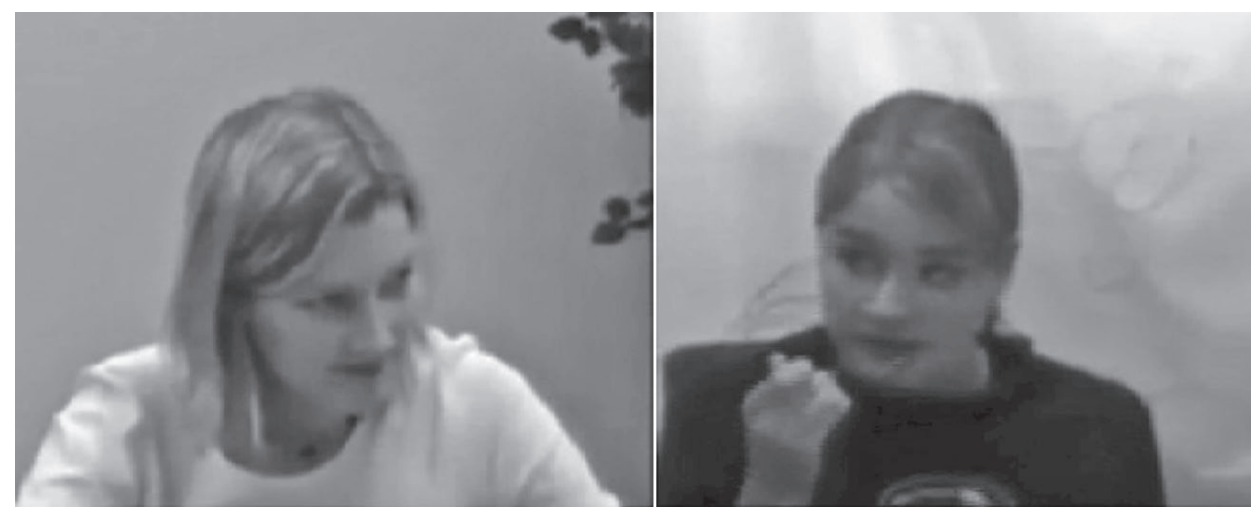

Figure 19

06 B: that they should wear /Fig19/ a ${ }^{\circ}$ skirt $^{\circ}$.

During the silence that follows (line 7), however, B starts to smile, simultaneously as she puts the spoon in her mouth (see Figure 20): the corners of her mouth get drawn up, and her cheeks appear to be raised. While taking the spoon away from her mouth, she turns her head toward A and the smile gets more intensive (Figure 21), after

A

B
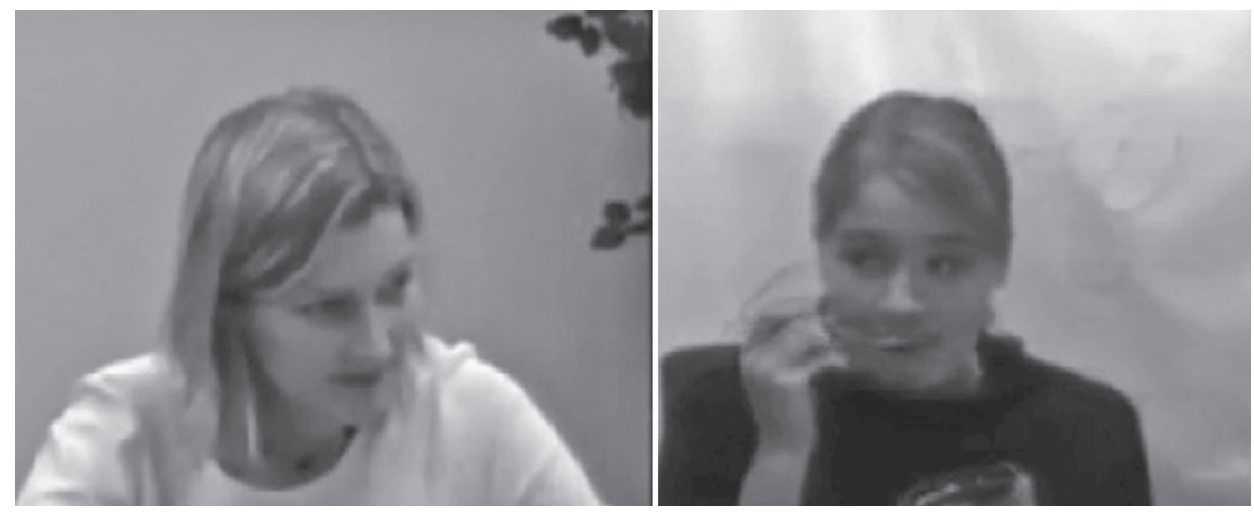

Figure 20

Silence in line 7

A B

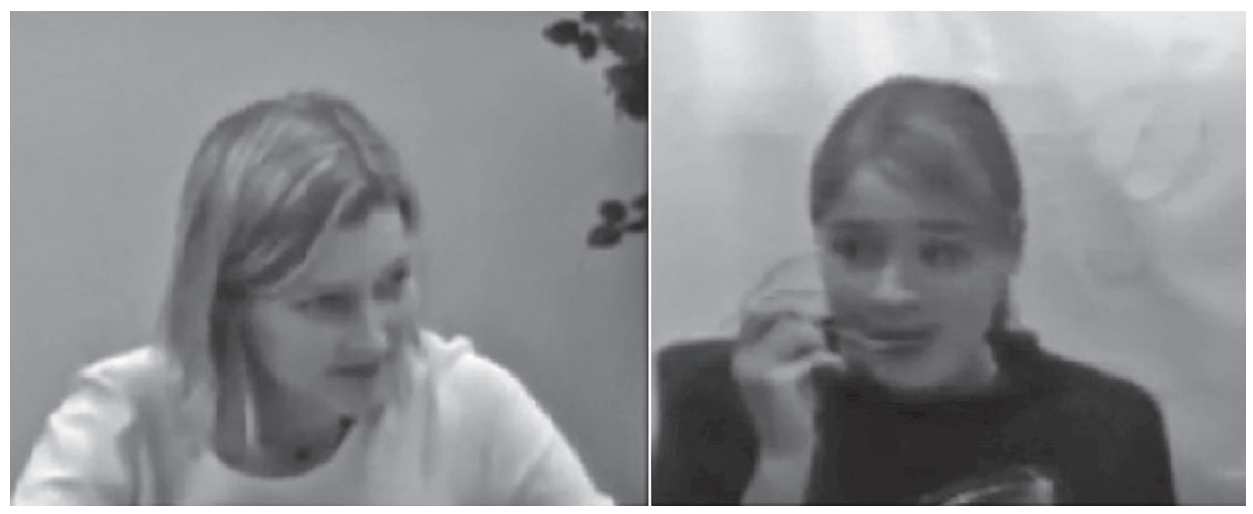

Figure 21

Silence in line 7 
A

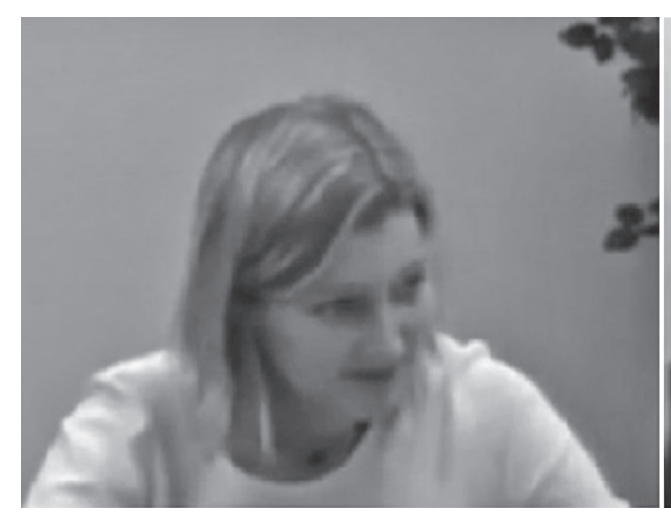

B

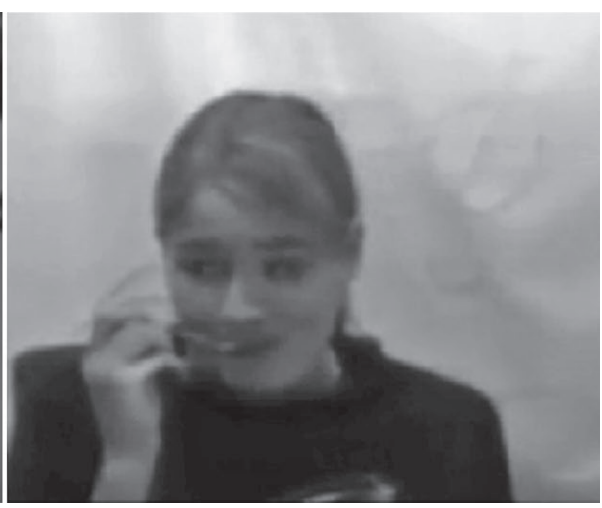

Figure 22

Silence in line 7

which she tilts her head slightly forward, and eventually (still during the silence in line 7), A starts to reciprocate the smile as the corners of her mouth raise (Figure 22).

Almost immediately after the change in the expression in her face, she begins to produce her first vocal response (line 8 , Figure 23).

A

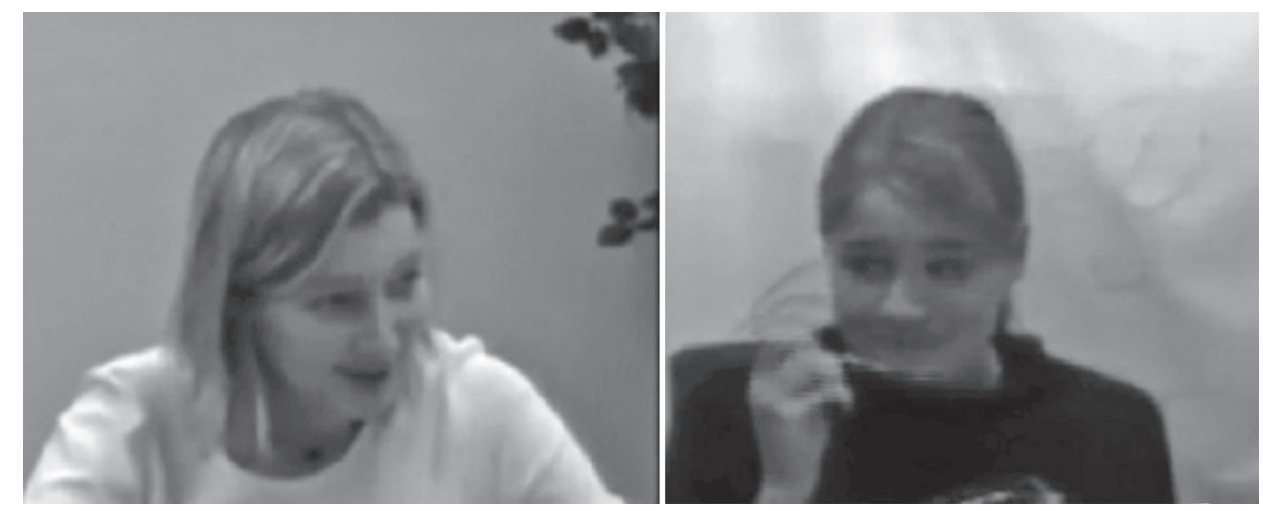

Figure 23

08 A: e[h/Fig23/:

B's smile, accompanied by the head moves toward the recipient, in Extract 4 serves as pursuit of response to the telling. It is in response to this smile that $A$, the recipient, begins to smile, and eventually produces the evaluative and appreciative vocal response to the telling in line 8 . They achieve a shared stance to the telling as something foolish or ridiculous first through their reciprocated smiles (see especially Figure 22) and thereafter through aligned vocalizations (lines 8-10).

The context of the telling strongly suggests that the teller may consider that what she is reporting is foolish or ridiculous: just before, the participants have laughed at male dress code in the same workplace. However, in the actual delivery of the announcement in lines 5-6, B seems to be avoiding emotional expressions: she offers no lexical cues for stance, her face is nonaffective, and her tone of voice also appears to be neutral. Therefore, her stance is implicit rather than explicit at 
the moment of the telling. This indeed seems to be one conventionalized way of making humorous remarks: to deliver them in a matter-of-fact way, leaving it to the recipient to infer the humor. As the recipient in Extract 4 does produce an immediate response, the teller starts to smile after the completion of the telling, thereby explicating the affective stance of her short anecdote. She now openly indicates what kind of response she is after.

Finally, we might ask, as in the earlier extracts, why was the pursuit here made with the face, and not by adding a new verbal element to the telling? In lines 3-6, B tells a potentially and implicitly funny anecdote, with neutral face, without indicating then and there that it is meant to be funny. The fun in the announcement needs to be inferred, as it were. Should she pursue affective response verbally, especially if she then would somehow explicate the fun for example by an evaluation, her line of action would be compromised, as it would become evident that the recipient did not get the concealed humor in the announcement. Therefore, facial expression that stretches the boundaries of action and thereby gives the recipient a new chance to react, and to evaluate the story at the right spot, may serve in preserving the initial line of action in an optimal way, while still accomplishing the pursuit.

\section{MODIFYING STANCE THROUGH FACIAL EXPRESSION}

The third type of facial pursuit of response transforms or modifies the emotional stance that there was in the telling. In these cases, the initial expression does display a stance - as in cases where the facial expression reinforces such stance, see Extracts 2 and 3-but instead of reinforcing the initial stance, the facial expression modifies it. This usage of facial expression seems to be apt in tellings involving self-criticism. Consider Extract 5. The participants are having a meal, and at the beginning of the extract, $B$ completes a sequence of assessments of the first course that they have just finished. In line 3, she begins a new topic and activity by making a noticing: she has spilled water on the table. The noticing is made in a neutral tone of voice. However, as it points out a slight misconduct by the speaker, it is hearable as involving self-criticism. The self-critical stance is also incorporated in the lexical choice, as B says "I've already spilled the water"-thus presupposing that spilling water is something she would be expected to do. A silence of one second ensues, whereafter the recipient, A, briefly laughs (line 6), thereby treating the matter as nonserious.

Extract 5

01 B: Se oli oikke hyvää.

That was very good.

02

03 B: Mä oon jo kaatanu /Fig 24/ve $\operatorname{det}^{\circ}$ /Fig 25/.

I've already spilled /Fig 24/the wa ${ }^{\circ}$ ter $^{\circ}$ /Fig 25/.

04

(1.0) / Fig 26/

05 B: hh/Fig 27/h 
07 (?): .hhhh

08

B: Kaadettiin niin /Fig 29/tä ${ }^{\circ} y d e t^{\circ}, k r h m$

We poured them so /Fig $\mathbf{2 9} /{ }^{\circ}$ full ${ }^{\circ}$, $\mathrm{krhm}$

10 A: $\underline{M m m m}$.

11

$(0.5)$

12 A: >Mull on tänään tota< (0.7) mä hüomaan et mul on tosi (0.3)

$>$ I have today like< $(0.7)$ I realize that I have a real $(0,3)$

13

homejuustopäivä ko,

blue cheese day as,

The shift from the teller's self-criticism to the recipient's laughter is orchestrated through the participants' visual conduct. Through her utterance in line 3, B is gazing down, toward her tray, with neutral face. Likewise, A is gazing down (Figure 24) until she,

A

B

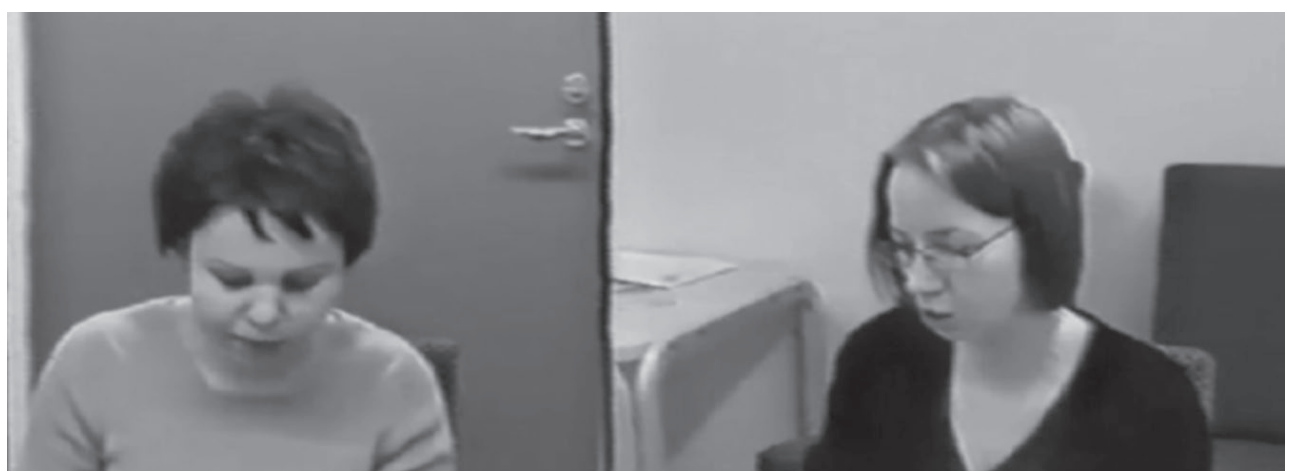

Figure 24

03 B: I've already spilled /Fig24/ the wa ${ }^{\circ}$ ter $^{\circ}$.

A

B

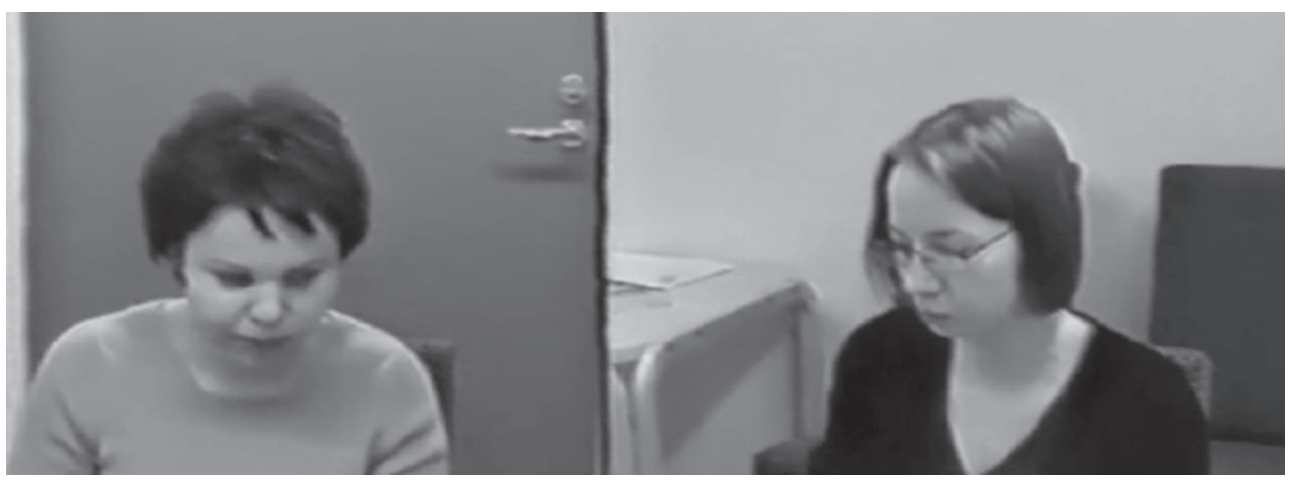

Figure 25

03 B: I've already spilled the wa ${ }^{\circ}$ ter $^{\circ}$ /Fig25/ 
during the last word of B's utterance, shifts her gaze toward B's glass (Figure 25) — thus making available for herself what B's noticing was about.

Silence of about 0.5 seconds ensues, during which the participants maintain their positions: A looking at the glass, B looking down. A is chewing her food, and both participants maintain neutral faces. Then B starts to shift her gaze toward A, moving her head slightly up and to the recipient, who almost immediately responds by a corresponding move to B. Simultaneously with her gaze shift, B starts to smile (see Figure 26). Her smile gets more intensive as she breathes out (Figure 27).

A B

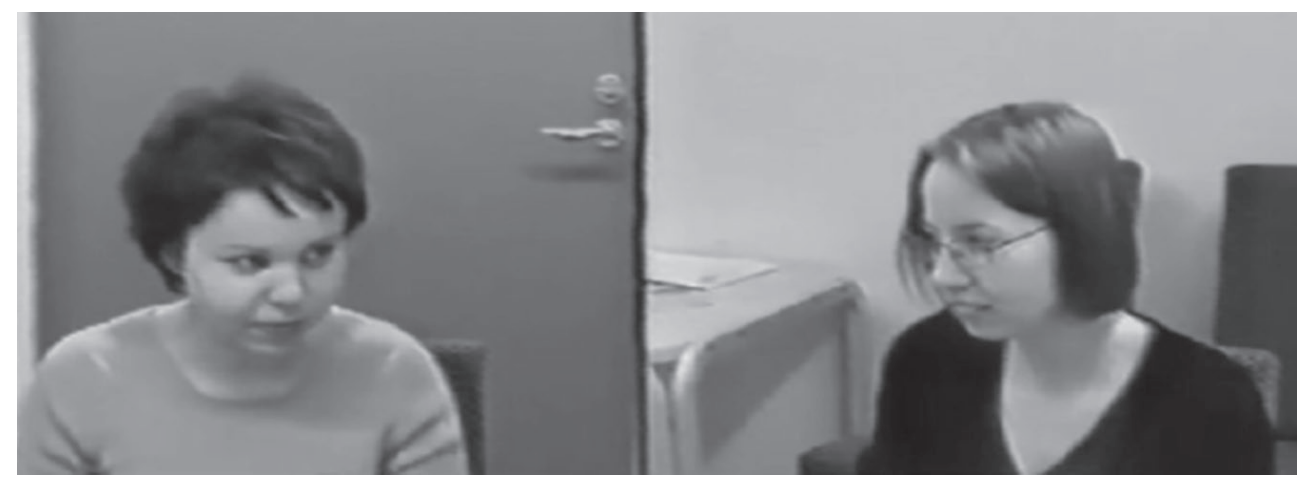

Figure 26

Silence in line 4.

A B

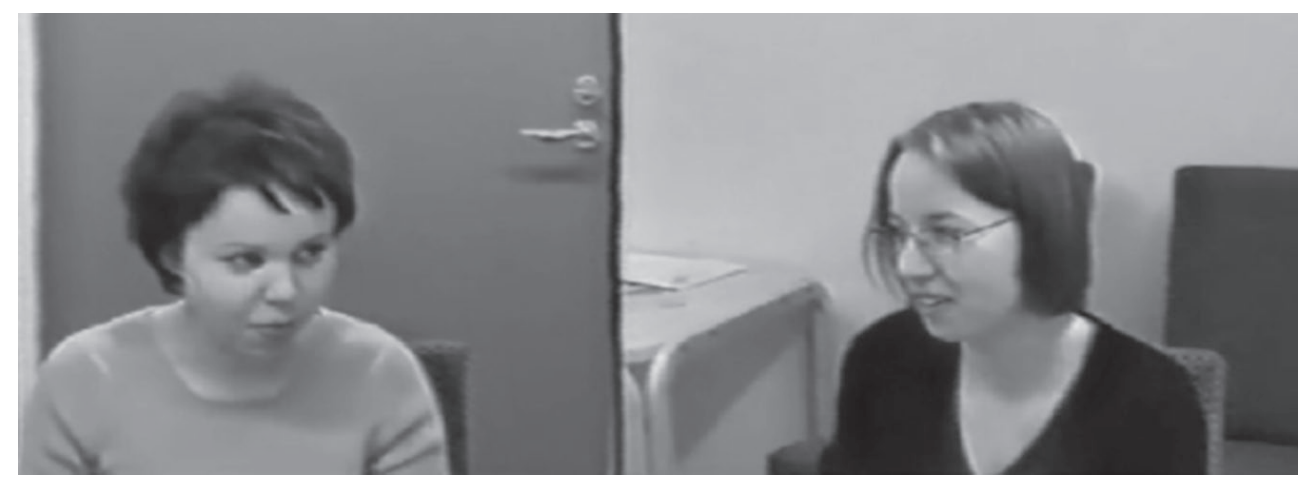

Figure 27

05 B: hh/Fig27/h

At the end of B's outbreath, A withdraws from mutual orientation, starts to smile, and shakes her head strongly to the left (Figure 28) and then back.

During the headshake, she also produces two laugh tokens (line 6). B withdraws her gaze from A quickly after the coparticipant's gaze withdrawal. Gazing down, she maintains her smile through lines 6-9 in the transcript. In line 9, while both participants are again gazing down, B smilingly gives an account of her misconduct (Figure 29). A new topic and action are started by $\mathrm{A}$ in line 12. 
A

B

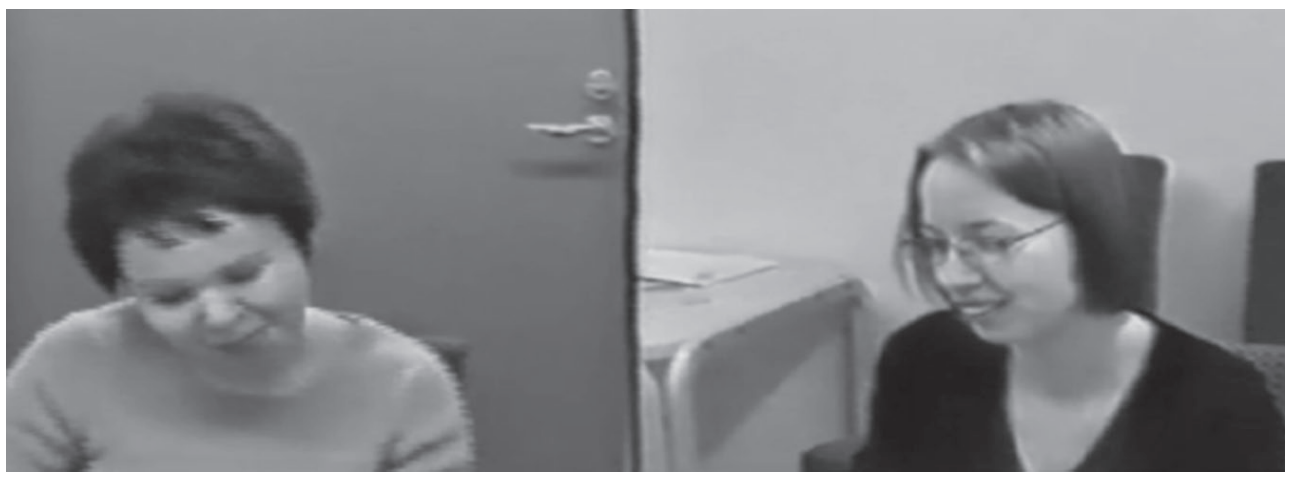

Figure 28

06 A: $m h i$ hi /Fig28/

A

B

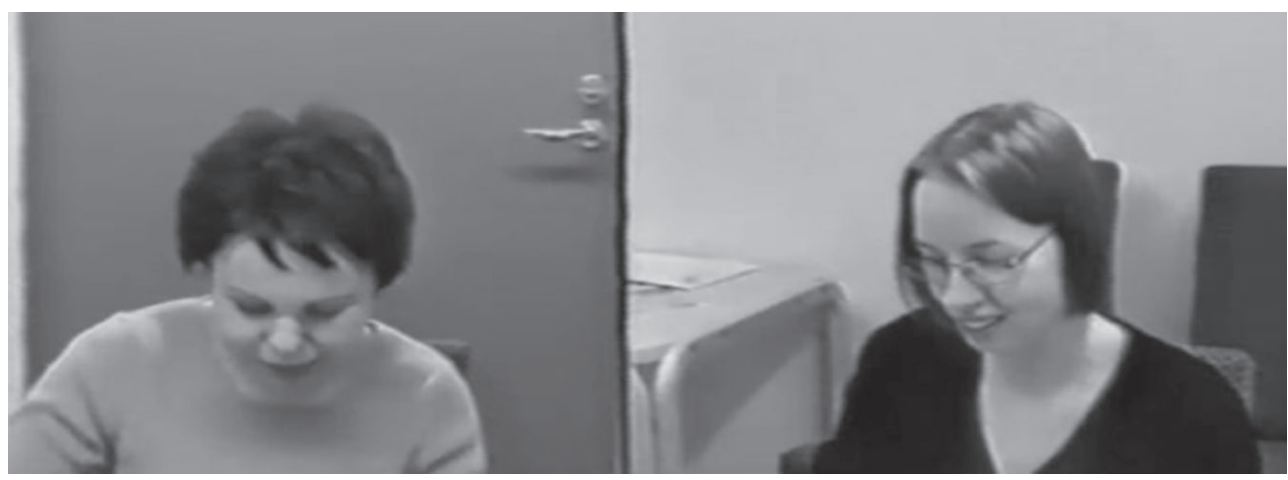

Figure 29

09 B: we poured them so /Fig29/ ${ }^{\circ}$ full ${ }^{\circ}, \mathrm{krhm}$

B's gaze and smile in lines 4 and 5 (Figures 26 and 27) modify the stance of the teller when facing a delayed response. They occur while the recipient of a noticing is silent. Given the lack of mutual gaze during the notification (Figures 24 and 25), it may not, at the time of its production, have involved a strong invitation for a response (see Stivers \& Rossano, 2010). However, as the speaker shifts her gaze to the recipient and smiles, a response is made relevant. Simultaneously, the emotional stance of the notification gets modified. During its occurrence, it observably involved the speaker's (at least mild) self-criticism; any humor possibly involved in the noticing was concealed and not oriented to by the recipient either. B's smile makes the stance light and humorous. It is this modified stance that the recipient orients herself to and reciprocates, through her laugh tokens, smile, and headshake, which as a Gestalt convey that the "misconduct" is amusing and nothing to worry about.

In Extract 5, the modification of stance through facial expression seems to serve as means for managing the complex relevancies of response to self-criticism. The preferred response to self-criticism is disagreement (Pomerantz, 1984b). In Extract 5, however, the speakers' notification that conveys self-criticism is hard to deny (unlike 
in assessments of appearances, for example): the water undeniably is there on the table, and the recipient is gazing at it (see Figure 25). Thus, the recipient is in an awkward situation where the preference organization would encourage her to distance herself from the speaker's notification, but her visible orientation to the environment does not afford that. A facial pursuit that modifies speakers' stance toward their telling from a self-blame into a laughable assertion efficiently saves the recipient from this awkward situation.

Our analysis has shown some variations of what we have called "facial pursuits of response." These consist of a particular combination of an observable change of the facial expression of the speaker and a head turn toward the coparticipant. Such facial pursuits can be found in a particular sequential location: at the closure of a telling with a stance, when response is delayed. We saw three types of semantic operations that were performed by the facial pursuits: reinforcing, explicating, and modifying the stance of the preceding telling. We also saw how such facial pursuits were reciprocated, providing the recipient was gazing at the speaker to observe the change in her facial expression. As compared with verbal pursuits, facial pursuits were different in one important respect. They could be situated within the transition space between turns of talk, adding a clarifying or modifying element to it without verbally respecifying and in this way slightly altering the focus of the action. In this way, facial pursuits were capable of retrieving an affiliating response from the coparticipant without overtly marking the preceding turn of talk as a trouble-source of some kind-they were capable of "stretching the boundaries of the ongoing action" (see also Peräkylä \& Ruusuvuori, 2006; Ruusuvuori \& Peräkylä, 2009).

\section{DISCUSSION}

At the beginning of this chapter, we pointed out that the face is special among the multimodal means of communication, as it is arguably specialized in the expression of emotion. This paper has shown that in spite of this specialized task, the face does not work on its own. We examined the intimate linkages between facial expression and the actions-such as storytelling, complaining, or self-criticism-carried out through spoken utterances. Our examples showed how facial expression of emotion was part of the multimodal organization of action at its particular junction. Our findings give further support to Goodwin \& Goodwin's (2000; see also this volume, chapter 2) conceptualization of emotion as multimodal stance display.

Facial pursuits display the stance of the speaker at the closure of a telling and give cues for a relevant way to respond to the telling. They facilitate an affiliating response, a reciprocal display of emotion. They emerge in situ, as a device to regain affective balance when facing possible disaffiliation and increased distance between the participants. With facial pursuits, the speaker thus regulates her immediate affective environment.

The facial expressions that we examined in this chapter have much in common with the verbal pursuits examined by Pomerantz (1984a) in nonvisual settings. As compared with verbal pursuits, one interactional advantage of the facial pursue arises from the capacity of the facial expression to stretch the boundaries of action. 
The facial pursuit, more than a verbal pursuit, leaves the initial action intact, as no new unit of talk is added to it. The teller does not have to explain or give grounds for her stance, when she reinforces, clarifies, or even modifies it through facial expression. Therefore, facial pursuit minimizes the rupture of progressivity of interaction and the breach of the affective relation between the participants.

In future studies, it would be worthwhile to compare systematically the uses of facial and verbal pursuits. Pomerantz's (1984a) study suggests that there is a relative ordering between the different types of verbal pursuit: clarifying referent encodes orientation to the least serious problem and hence, it can be the first choice of pursuit; while reviewing common knowledge and revising opinion orient to more of a problem, and they are resorted to only if clarifying reference fails or is not relevant. Our observations suggest the possibility that there might be similar sorts of relative ordering between facial and verbal pursuits: due to their capacity to preserve the prior action, and to minimize the nonprogressivity, facial pursuit might be something to be tried first. That was indeed the case in Extract 3: the facial pursuit was the speaker's first effort to pursue response, and as it failed, the speaker resorted to verbal pursuits. More systematic comparison of facial and verbal pursuits could clarify the matter.

Our observations lend themselves for elaborating some of the key ideas of regulation of emotion. For Gross and Thompson (2007, pp. 10-16), emotion regulation has five facets: situation selection, situation modification, attentional deployment, cognitive change, and response modulation. Each of these can be investigated from the point of view of an individual actor. However, it appears that interactional research such as that reported in this chapter can elaborate what these facets might involve. Our results address all but the first facet (situation selection).

The most obvious linkage concerns response modulation, which for Gross and Thompson (2007, p. 15) involves "influencing physiological, experiential or behavioral responding." An individual's means of response modulation vary from drugs, exercise, and relaxation to reflection and verbalization of the emotional experience. The picture of emotional response modulation becomes rather different if we focus on interaction process rather than on individual. We showed that a key aspect of what Gross and Thompson would call "behavioral response", that is, facial expression of emotion, is very intimately linked to the organization of interaction. The interactants timed their facial expression in relation to turn transition (at the completion of utterances) and the organization of larger activities (at the end of activities such as storytelling, troubles telling, complaining). In producing these expressions, they were attentive to their recipient's actions, producing facial pursuits when the recipients had not reciprocated the teller's stance. Thus, response modulation was adapted to the momentary contingencies of the interaction process. We also showed that facial expression was there to elicit consequences in the cointeractant. Thus, modulation of emotional expression is not only as it were looking backward (downregulating or upregulating an emotional response to a trigger) but it is also looking forward, in inviting the cointeractant into relevant emotional activity, in this case, to reciprocate the stance of the telling.

Interaction is also consequential to issues pertaining to situation modification, which involves efforts to change some features in a situation that triggers emotions 
in individuals. Gross and Thompson (2007, p. 12) point out that emotional expressions can in themselves modify the situation: crying, for example, halting an escalation of anger. Our observations are in line with this. We showed how the emotional relevance of a situation is modified moment by moment through the subtle choices that the interactants make in designing their vocal and nonvocal actions. The first speakers (the tellers) in our data extracts were monitoring the recipient actions at the completion of the telling and designed their further actions accordingly (pursuing response through facial expression if the recipient had not reciprocated the stance of the telling). Thus, for the first speakers, the recipient action was a key feature of the situation. Then, if an affiliating response did not occur at the moment where it would be expected, the first speakers reinforced, explicated, or modified their own stance displays, thereby modifying the situation to be responded to by the second speaker. Our observations demonstrate how the situation modification is a thoroughly reflexive process, as the interactants' momentary actions constitute the situation for the cointeractants.

Our observations also speak to attentional deployment, which for Gross and Thompson (2007, p. 13) involves the ways in which "individuals direct their attention within a given situation in order to influence their emotions." Attention can be shifted away from emotion-eliciting stimuli, or it can be drawn to them. A recurrent feature in our extracts incorporates interactive attentional deployment. In producing their facial pursuits of response, the interactants regularly moved their heads toward the recipients while changing their facial expression. In Extract 5, the head move co-occurred with the speaker turning her gaze to the recipient, but in most cases the speaker and recipient had already established mutual orientation when the speaker produced the facial expression couched by the head movements. Our case-by-case analysis does not warrant any conclusions, but it is a sensible hypothesis that these systematic head movements toward the recipient, concomitant with facial expressions, served to intensify the attention that the gazing recipients pays to them. Thus, our observations suggest that the tellers were at key moments (at the completion of a telling that had not received stance reciprocation) not only displaying affect through their face, but they were also engaged in a particular activity, head movement, to draw their recipients' attention to that display. Attentional deployment, as part of the interactional regulation of emotion, is thus a momentarily unfolding collaborative achievement.

Cognitive change is yet another facet of emotion regulation that our observations address. In Gross and Thompson's terms (2007, p. 14) it involves “changing how we appraise the situation we are in to alter its emotional significance." Interactional management of cognitive change was taking place in cases where the first speakers explicated (Extract 4) or modified (Extract 5) the emotional valence of their telling through their postcompletion facial expressions. The facial expressions served as invitations for the recipient to reconsider, at that very moment, the stance attached to the telling just completed. By their responses, the recipients then showed the corresponding "reappraised" stance-in Extract 4, unambiguously, and in Extract 5, ambiguously. So, also cognitive change can be seen as an interactional achievement.

In existing literature, the concept of emotion regulation is predominantly used to refer to regulatory processes within individuals. As conversation analysts, we are 
not investigating individuals but interactions. However, as the discussion above shows, there seem to be sensible linkages and parallels between the way in which the individual-centered process of emotion regulation is understood, and our findings on interactional regulation of expressions of emotion. Individual regulation and interactional regulation may be two sides of the same coin. That is what Beebe and Lachmann (2002, p. 22) suggest: there is "an intimate connection between self-and interaction regulation." Basically, they argue that the same behaviors that entail interactional regulation of emotion, also serve for self-regulation, and that the interactional regulation and the self-regulation for that reason comprise a system.

Our data as such do not give us access to self-regulation, as they show only interactional regulation. But the parallels between our findings and the way in which researchers have broken down the concept of individual regulation of emotion are in line with the "systemic" argument put forward by Beebe and Lachmann. From the point of view of interaction research, it appears that the practices of the interactional regulation of emotion can serve as the springboard of the self-regulatory processes. Situation modification, attentional deployment, cognitive changes, and response modulation take place in and through interaction, and these interactive processes may be the substrate from which the individuals' emotion regulation arises. 